\title{
A novel diabetes typology: towards precision diabetology from pathogenesis to treatment
}

\author{
Christian Herder ${ }^{1,2,3}$ (D) Michael Roden ${ }^{1,2,3}$ (I) \\ Received: 25 June 2021 / Accepted: 4 October 2021 / Published online: 4 January 2022 \\ (C) The Author(s) 2022
}

\begin{abstract}
The current classification of diabetes, based on hyperglycaemia, islet-directed antibodies and some insufficiently defined clinical features, does not reflect differences in aetiological mechanisms and in the clinical course of people with diabetes. This review discusses evidence from recent studies addressing the complexity of diabetes by proposing novel subgroups (subtypes) of diabetes. The most widely replicated and validated approach identified, in addition to severe autoimmune diabetes, four subgroups designated severe insulin-deficient diabetes, severe insulin-resistant diabetes, mild obesity-related diabetes and mild age-related diabetes subgroups. These subgroups display distinct patterns of clinical features, disease progression and onset of comorbidities and complications, with severe insulin-resistant diabetes showing the highest risk for cardiovascular, kidney and fatty liver diseases. While it has been suggested that people in these subgroups would benefit from stratified treatments, RCTs are required to assess the clinical utility of any reclassification effort. Several methodological and practical issues also need further study: the statistical approach used to define subgroups and derive recommendations for diabetes care; the stability of subgroups over time; the optimal dataset (e.g. phenotypic vs genotypic) for reclassification; the transethnic generalisability of findings; and the applicability in clinical routine care. Despite these open questions, the concept of a new classification of diabetes has already allowed researchers to gain more insight into the colourful picture of diabetes and has stimulated progress in this field so that precision diabetology may become reality in the future.
\end{abstract}

Keywords Clustering $\cdot$ Complications $\cdot$ Diabetes subgroups $\cdot$ Personalised medicine $\cdot$ Precision medicine $\cdot$ Reclassification Review

Christian Herder

christian.herder@ddz.de

Michael Roden

michael.roden@ddz.de

$1 \quad$ Institute for Clinical Diabetology, German Diabetes Center (Deutsches Diabetes-Zentrum/DDZ), Leibniz Center for Diabetes Research at Heinrich-Heine-University Düsseldorf, Düsseldorf, Germany

2 Department of Endocrinology and Diabetology, Medical Faculty and University Hospital Düsseldorf, Heinrich-Heine-University Düsseldorf, Düsseldorf, Germany

3 German Center for Diabetes Research (DZD), Partner Düsseldorf, München-Neuherberg, Germany

$\begin{array}{ll}\text { Abbreviations } \\ \text { ADOPT } & \text { A Diabetes Outcome Progressive Trial } \\ \text { AHEAD } & \text { Action for Health in Diabetes } \\ \text { ANDIS } & \text { All New Diabetics in Scania } \\ \text { ANGPTL8 } & \text { Angiopoietin-like protein } 8 \\ \text { CAN } & \text { Cardiovascular autonomic neuropathy } \\ \text { CASP-8 } & \text { Caspase-8 } \\ \text { CKD } & \text { Chronic kidney disease } \\ \text { DSPN } & \text { Distal sensorimotor polyneuropathy } \\ \text { EN-RAGE } & \text { S100 calcium-binding protein A12 } \\ \text { GDS } & \text { German Diabetes Study } \\ \text { GLP-1RA } & \text { Glucagon-like peptide-1 receptor agonist } \\ \text { hSCRP } & \text { High-sensitivity C-reactive protein } \\ \text { MARD } & \text { Mild age-related diabetes } \\ \text { MOD } & \text { Mild obesity-related diabetes }\end{array}$

Abbreviations

AHEAD Action for Health in Diabetes

ew in Scania

CASP-8 Caspase-8

EN-RAGE S100 calcium-binding protein A12

GDS German Diabetes Study

GLP-1RA Glucagon-like peptide-1 receptor agonist

MARD Mild age-related diabetes

Mild obesity-related diabetes 


$\begin{array}{ll}\text { NAFLD } & \text { Non-alcoholic fatty liver disease } \\ \text { PRS } & \text { Polygenic risk score } \\ \text { SAID } & \text { Severe autoimmune diabetes } \\ \text { SGLT2i } & \text { Sodium-glucose cotransporter 2 inhibitor } \\ \text { SIDD } & \text { Severe insulin-deficient diabetes } \\ \text { SIRD } & \text { Severe insulin-resistant diabetes } \\ \text { VNDS } & \text { Verona Newly Diagnosed Type 2 Diabetes } \\ & \text { Study }\end{array}$

\section{Rationale for diabetes reclassification}

The observation that people with diabetes have different phenotypes has led to repeated attempts to classify the main diabetes types $[1,2]$. Electronic supplementary material (ESM) Table 1 summarises the key efforts in this evolution. People with diabetes show a broad variation in the main features of diabetes (i.e. insulin resistance and beta cell dysfunction [3-6]) as a result of the combined effects of (epi)genetic, environmental and lifestyle factors and their different contributions in different individuals. A recently proposed 'palette model' conceptualises the interaction of these factors [3]. People at risk of diabetes may have impairments in multiple processes such as islet development, islet function, autoimmunity, inflammation, insulin sensitivity, incretin activity and adipose tissue function (considered as 'base colours'). Every individual is positioned somewhere within the spectrum of the phenotypic variation of each trait as determined by their genetic variation and non-genetic exposures modifying these processes, and the sum (or mixture) of all trait variations represents the overall estimate of metabolic health and diabetes status [3]. However, this pathophysiological heterogeneity is not captured by current position statements and guidelines for diagnosis and treatment of diabetes $[7,8]$.

Differences in risk factors and pathophysiological mechanisms are thought to drive the heterogeneity in preclinical abnormalities, prevalence of comorbidities and clinical complications already seen at diagnosis of diabetes [5, 9]. People with diabetes further vary in the progression of their disease and in the incidence of diabetes-related complications despite comparable glycaemic control.

Any reclassification effort should be seen as an example of precision medicine or 'precision diabetology' aiming to deconstruct the heterogeneity of diabetes. Advances in the management of monogenic forms of diabetes (neonatal diabetes, MODY) represent a successful proof-of-concept for a reclassification of diabetes [10]. Currently, however, relatively few people with diabetes are affected by monogenic diabetes so this may serve as an example for personalised medicine based on mutations in single genes [11] rather than the precision medicine approach that is required for type 1 and type 2 diabetes, which are both polygenic and multifactorial [12].

In the context of type 1 and type 2 diabetes, the ultimate purpose of precision diabetology is the development of stratified prevention and treatment for subgroups of people with different risk profiles. These options range from refined screening and monitoring intervals, recommendations for tailored lifestyle interventions, to targeted but not individualised drug treatment. Clinical benefits envisaged include fewer adverse effects and ideally a delay of the onset of diabetes and its complications, lower morbidity and mortality and an economic use of resources [13].

The aim of this review is to provide an up-to-date, concise overview of studies on diabetes reclassification, their implications, and also inherent practical and methodological challenges, with a specific focus on recent definitions of subgroups of type 2 diabetes and the risk of complications in these subgroups. With respect to subgroups and endotypes of type 1 diabetes, we would like to refer the reader to recent excellent reviews covering aspects of precision diabetology for this diabetes type $[8,14]$.

\section{Variability of disease presentation and progression}

One approach to study the heterogeneity of diabetes relies on cohorts of people included at or shortly after the diagnosis of diabetes [5]. Even though the duration of hyperglycaemia before diabetes diagnosis is unknown, these cohorts allow the investigation of clinical characteristics that are not yet confounded by long-term excessive hyperglycaemia and pharmacological treatment. Examples are the German Diabetes Study (GDS [5]), the Verona Newly Diagnosed Type 2 Diabetes Study (VNDS [15]) and the All New Diabetics in Scania (ANDIS [6]) cohorts.

The comprehensive phenotyping in the GDS, using goldstandard methodology, demonstrated large interindividual differences in people within 12 months of their diagnosis of diabetes regarding insulin sensitivity, beta cell function, isletdirected autoantibodies, blood lipids and BP $[5,16]$. The variability in disease severity or progression is reflected by differences between subgroups of type 2 diabetes regarding diabetes-related complications such as chronic kidney disease (CKD), distal sensorimotor polyneuropathy (DSPN), cardiovascular autonomic neuropathy (CAN), retinopathy and nonalcoholic fatty liver disease (NAFLD) [5, 16, 17].

The VNDS enrols people with type 2 diabetes within 6 months of their diagnosis. Assessment of diabetes-related complications indicated a high variability in their presentation and progression $[15,18]$; the prevalence of one or more diabetes-related complications (CVD, nephropathy, DSPN, 
CAN, retinopathy) already present at study enrolment was found to be $49.2 \%$ [9].

The ANDIS cohort includes incident cases of diabetes and reported a marked prevalence of NAFLD at baseline (although only based on surrogate measurement by alanine aminotransferase) and the development of CKD, retinopathy and CVD in the first years after the diagnosis of diabetes [6].

In addition, people with diabetes differ with respect to inherited factors. The application of a polygenic risk score (PRS) based on $>136,000$ variants in the UK Biobank demonstrated a prevalence of type 2 diabetes of $1.2 \%$ and $11.2 \%$ in the lowest and highest $2.5 \%$ of the PRS distribution, respectively, revealing an almost tenfold difference [19].

Taken together, these studies highlight the substantial variability in the pathogenic and clinical characteristics of the large population of people commonly designated as having type 2 diabetes.

\section{Novel subtypes of diabetes reflecting differences in disease development and progression}

Reclassification methods From a methodological perspective, different clustering algorithms have been used to reclassify people with diabetes [20-25]. Topology-based analysis [21] and Bayesian non-negative matrix factorisation clustering [22] are widely applied procedures for discovering groups of related observations (e.g. subgroups of people with diabetes) using high-dimensional data such as electronic medical records or omics data. Cluster analysis based on the $k$-means or the partitioning around medoids methods $[6,23]$ break large datasets up into subgroups by minimising the distance between data points labelled to be in a cluster and a point designated as the centre of that cluster. These methods require that the optimal number of clusters $(k)$ needs to be known a priori (i.e. evaluated with other methods). In contrast, latentclass trajectory analysis is a longitudinal analysis method using repeated measures of dependent variables as a function of time to identify subgroups of people who differ in trajectories (e.g. in glucose response curves) [24, 25].

In addition to these methods, reclassification studies made use of datasets that differed widely in the type and number of variables. One clustering approach, using high-dimensional electronic medical records and extensive genotype data, identified three subtypes of type 2 diabetes enriched in CVD, nephropathy, retinopathy, neurological diseases and cancer [21]. A second approach used data for 94 type 2 diabetesassociated gene variants and 47 diabetes-related traits to subgroup genetic loci according to mechanistic pathways and to relate the clinical characteristics of people with type 2 diabetes to their genetic risk scores [22]. This study found two clusters of genetic loci related to insulin deficiency and three related to insulin resistance. Individuals with high genetic risk scores in the respective clusters also differed in obesity, lipids, hypertension, kidney function and CVD [22].

From a clinical perspective, clustering algorithms based on available patient data would be highly attractive. One study used latent-class trajectory analysis based on mixed-meal tolerance tests in people with newly diagnosed type 2 diabetes [25] and identified three subgroups based on their glucose response patterns. Thus, this method represents another classification approach closely related to insulin resistance and insulin secretion as the pathophysiological hallmarks of type 2 diabetes.

Diabetes subgroups The most frequently replicated study in this field used both hierarchical and $k$-means clustering in Swedish people with newly diagnosed diabetes, with the following six variables as input: GAD antibodies; age at diagnosis; $\mathrm{BMI}$ at diagnosis; $\mathrm{HbA}_{1 \mathrm{c}}$; and HOMA-2 estimates of insulin resistance and beta cell function calculated from fasting glucose and C-peptide [6]. The resulting subgroups (subtypes) were designated as severe autoimmune diabetes (SAID), severe insulin-deficient diabetes (SIDD), severe insulin-resistant diabetes (SIRD), mild obesity-related diabetes (MOD) and mild age-related diabetes (MARD) [6] (Table 1). This concept has been replicated in cohorts from Europe, North America and Asia despite varying disease duration since diabetes diagnosis [26-32]. The SAID subgroup comprises people who are otherwise classified as having type 1 diabetes (including those previously termed latent autoimmune diabetes of adults), whereas SIDD, SIRD, MOD and MARD represent novel entities of type 2 diabetes. The subgroups also differ with respect to prevalence and/or risk of complications (Table 1). In line with the predominant insulin deficiency, ketoacidosis at diagnosis is most frequent in SAID and SIDD [6]. Retinopathy, DSPN and CAN are observed most often in SIDD [6, 26], while CKD and NAFLD are most prevalent in SIRD [6, 26, 29]. Adjusted risk ratios for prevalent erectile dysfunction are highest for SIDD and SIRD [33]. Although the subgroups differ in their cardiovascular risk, these differences did not remain statistically significant after adjustment for age and sex in the ANDIS cohort [6] or after more comprehensive adjustment for multiple covariables in a Japanese cohort [29].

Subgroup variables The clinical relevance of the novel subgroups has been assessed in multiple cohorts including ethnically diverse populations that lack some of the aforementioned clustering variables (most often C-peptide measurements). Partial replication of the subgroup classification and differential risk of complications was reported in cohorts from Europe [34, 35], the USA [36, 37], Mexico [38], Latin America and the Caribbean [39], India [40] and China [41] and in large international trial populations (DEVOTE/ 
Table 1 Metabolic characteristics and diabetes-related complications of individuals in the novel diabetes subgroups

\begin{tabular}{|c|c|c|}
\hline $\begin{array}{l}\text { Diabetes } \\
\text { subgroup }\end{array}$ & $\begin{array}{l}\text { Metabolic } \\
\text { characteristics }\end{array}$ & Diabetes-related complications \\
\hline SAID & $\begin{array}{l}\text { Early-onset diabetes } \\
\text { Low BMI } \\
\text { High } \mathrm{HbA}_{1 \mathrm{c}} \\
\text { Insulin deficiency } \\
\text { Presence of GADA }\end{array}$ & $\begin{array}{l}\text { Ketoacidosis at diagnosis [6] } \\
\text { High risk of retinopathy [29] } \\
\text { High incidence of CKD but dependent on baseline eGFR [28] }\end{array}$ \\
\hline SIDD & $\begin{array}{l}\text { Early-onset diabetes } \\
\text { Low BMI } \\
\text { High } \mathrm{HbA}_{1 \mathrm{c}} \\
\text { Insulin deficiency } \\
\text { GADA negative }\end{array}$ & $\begin{array}{l}\text { Ketoacidosis at diagnosis [6] } \\
\text { High risk of retinopathy [6] } \\
\text { Highest prevalence of DSPN [26] } \\
\text { Highest prevalence of CAN [26] } \\
\text { High prevalence of erectile dysfunction [33] }\end{array}$ \\
\hline SIRD & $\begin{array}{l}\text { Late-onset diabetes } \\
\text { High BMI } \\
\text { Most } \\
\text { insulin-resistant } \\
\text { GADA negative }\end{array}$ & $\begin{array}{l}\text { Highest liver fat content, fatty liver index, NAFLD fibrosis score and } \\
\text { prevalence of NAFLD }[6,26,29] \\
\text { Highest risk for macroalbuminuria, CKD and end-stage renal disease } \\
{[6,26,29]} \\
\text { High risk of coronary event and stroke (dependent on age and sex) [6] } \\
\text { High prevalence of erectile dysfunction [33] }\end{array}$ \\
\hline MOD & $\begin{array}{l}\text { Early-onset diabetes } \\
\text { High BMI } \\
\text { Intermediate insulin } \\
\text { resistance } \\
\text { GADA negative }\end{array}$ & $\begin{array}{l}\text { Intermediate prevalence and risk of diabetes-related complications [6, } \\
26]\end{array}$ \\
\hline MARD & $\begin{array}{l}\text { Late-onset diabetes } \\
\text { Low BMI } \\
\text { GADA negative }\end{array}$ & High risk of coronary events and stroke (dependent on age and sex) [6] \\
\hline
\end{tabular}

Metabolic characteristics are based on European cohorts with newly diagnosed diabetes using GAD antibodies, age at diagnosis, $\mathrm{BMI}$ at diagnosis, $\mathrm{HbA}_{1 \mathrm{c}}$ and HOMA-2 estimates of insulin resistance and beta cell function calculated from fasting glucose and fasting $\mathrm{C}$-peptide concentrations as clustering variables $[6,26]$

GADA, GAD antibodies
LEADER/SUSTAIN-6 [42]) (Table 2). At present it is not known whether C-peptide or insulin are required to identify SIRD, so it would be informative to compare different combinations of clustering variables (e.g. with and without Cpeptide or insulin) in the same cohorts, to better understand their relevance for reclassification.

Only a few studies have explored biomarkers and pathways underlying differences between subgroups that could determine susceptibility to diabetes-related complications. Given the role of lipid metabolism in diabetes, it is noteworthy that serum triacylglycerol levels were found to be highest and HDL-cholesterol levels lowest in SIRD, while there were no differences in total or LDL-cholesterol [26, 29, 43]. Circulating levels of angiopoietin-like protein 8 (ANGPTL8), a regulator of lipid metabolism, were higher in SIDD, SIRD and MARD than in MOD [44]. However, these differences were not adjusted for the clustering variables.

Subgroup differences in inflammation Circulating levels of high-sensitivity C-reactive protein (hsCRP) were highest in
SIRD and MOD [29]. The association of circulating triacylglycerols and inflammatory processes with insulin resistance is in line with the uniform mechanism underlying common insulin resistance in humans [45]. A multimarker approach in the GDS found that 23 biomarkers of inflammation differed between the subgroups, with biomarker levels in general being highest in SIRD and lowest in SIDD [46]. After adjustment for the clustering variables, serum caspase-8 (CASP-8), S100 calcium-binding protein A12 (EN-RAGE) and IL-6 showed at least one pairwise difference between the subgroups. The association between inflammation and insulin resistance reflects the contribution of inflammation-related processes to SIRD, whereas inflammatory processes appear less relevant in SIDD [46]. A second study in this cohort showed that the SIRD subgroup also had high leucocyte numbers and the highest $\mathrm{CD}^{+} \mathrm{T}$ cell percentages, thereby demonstrating different immune cell frequencies between subgroups and highlighting the proinflammatory characteristics of SIRD [47]. Of note, studies on autoimmune diabetes identified both genetic and epigenetic determinants of $\mathrm{T}$ cell function, with 
Table 2 Overview of clustering studies using alternative demographic and clinical variables to identify subgroups of diabetes

\begin{tabular}{|c|c|c|c|c|}
\hline Cohort characteristic & Clustering variables & Subgroups & Specific findings & Ref. \\
\hline $\begin{array}{l}\text { VNDS, Italy } \\
\text { (739 with T2D) }\end{array}$ & $\begin{array}{l}\text { Age, BMI, HOMA-2 estimates of } \\
\text { beta cell function and insulin } \\
\text { resistance }\end{array}$ & $\begin{array}{l}\text { SIDD } \\
\text { MARD } \\
\text { OIRD } \\
\text { EOD }\end{array}$ & $\begin{array}{l}\text { Replication of SIDD and MARD } \\
\text { OIRD comprising MOD and SIRD } \\
\text { MARD associated with CVD } \\
\text { Highest } \mathrm{HbA}_{1 \mathrm{c}} \text { after 14-month } \\
\text { follow-up in SIDD }\end{array}$ & [34] \\
\hline $\begin{array}{l}\text { Three cohort studies from } \\
\text { Europe: Hoorn DCS; } \\
\text { GoDARTS; ANDIS } \\
\text { (15,940 people with T2D, } \\
\text { within } 2 \text { years of } \\
\text { diagnosis) }\end{array}$ & $\begin{array}{l}\text { Age, BMI, } \mathrm{HbA}_{1 \mathrm{c}} \text {, random or fasting } \\
\text { C-peptide, HDL-cholesterol }\end{array}$ & Five distinct T2D subgroups & $\begin{array}{l}\text { Three subgroups could be mapped } \\
\text { back to the original ANDIS } \\
\text { clusters (SIDD, SIRD, MOD) } \\
\text { Two subgroups (MD and MDH } \\
\text { related to MARD) } \\
\text { Progression to insulin fastest for } \\
\text { SIDD and slowest for MDH }\end{array}$ & [35] \\
\hline $\begin{array}{l}\text { MASALA and MESA } \\
\text { multi-ethnic cohorts } \\
\text { from USA } \\
\text { (1293 people with } \\
\text { diabetes; mean } \\
\text { diabetes duration } \\
5.7 \text { years) }\end{array}$ & $\begin{array}{l}\text { Age at diagnosis, BMI } \\
\mathrm{HbA}_{1 \mathrm{c}}, \mathrm{HOMA} \text { estimates of beta cell } \\
\quad \text { function and insulin resistance }\end{array}$ & $\begin{array}{l}\text { Five T2D subgroups: older age, } \\
\text { severe hyperglycaemia, severe } \\
\text { obesity, younger age at onset; } \\
\text { requiring insulin medication use }\end{array}$ & $\begin{array}{l}\text { Older age most common subgroup } \\
\text { for all race/ethnicities apart from } \\
\text { South Asians } \\
\text { Severe hyperglycaemia subgroup } \\
\text { most frequent in South Asians } \\
\text { Risk for renal complications and } \\
\text { subclinical CVD differed by } \\
\text { subgroup and by race/ethnicity }\end{array}$ & [36] \\
\hline $\begin{array}{l}\text { Look AHEAD } \\
\text { (5145 overweight/obese } \\
\text { people with T2D and } \\
10 \text { years of lifestyle } \\
\text { intervention or control } \\
\text { group) }\end{array}$ & Age at diagnosis, $\mathrm{BMI}, \mathrm{WC}, \mathrm{HbA}_{1 \mathrm{c}}$ & $\begin{array}{l}\text { Four subgroups: by older age at } \\
\text { diabetes onset; poor glucose } \\
\text { control; severe obesity; younger } \\
\text { age at diabetes onset }\end{array}$ & $\begin{array}{l}\text { Interaction between lifestyle } \\
\text { intervention and diabetes } \\
\text { subgroups for three composite } \\
\text { cardiovascular outcomes } \\
\text { Increased cardiovascular risk for } \\
\text { people in subgroup with poor } \\
\text { glucose control randomised to } \\
\text { lifestyle intervention }\end{array}$ & [37] \\
\hline $\begin{array}{l}\text { NHANES (USA) and } \\
\text { four Mexican cohorts } \\
\text { (1758 people with T2D in } \\
\text { NHANES; } 9887 \\
\text { people with T2D in the } \\
\text { open-population } \\
\text { Mexican cohorts) }\end{array}$ & $\begin{array}{l}\text { Models based on different } \\
\text { combinations of years since } \\
\text { diagnosis, BMI, } \mathrm{HbA}_{1 \mathrm{c}}, \\
\text { HOMA-2 estimates of beta cell } \\
\text { function and insulin resistance, } \\
\text { fasting plasma glucose, } \\
\text { METS-IR, METS-VF, age at } \\
\text { diabetes onset }\end{array}$ & $\begin{array}{l}\text { Four subgroups: obesity-related; } \\
\text { insulin-deficient; insulin-resistant; } \\
\text { age-related }\end{array}$ & $\begin{array}{l}\text { Risk of retinopathy highest for } \\
\text { insulin-deficient subgroup and } \\
\text { lowest for obesity-related } \\
\text { subgroup } \\
\text { Subgroup transitions observed after } \\
3 \text { months, } 1 \text { year and } 2 \text { years }\end{array}$ & [38] \\
\hline $\begin{array}{l}\text { Thirteen cohort studies } \\
\text { from nine countries in } \\
\text { Latin America and the } \\
\text { Caribbean } \\
\text { (8361 people with T2D) }\end{array}$ & $\begin{array}{l}\text { Age, sex, BMI, WC, } \\
\text { systolic/diastolic BP, T2D family } \\
\text { history }\end{array}$ & $\begin{array}{l}\text { Four clusters: Cluster } 0 \text {, highest BP; } \\
\text { Cluster 1, highest BMI and WC, } \\
\text { highest proportion of positive } \\
\text { family history of diabetes; Cluster } \\
2 \text {, most beneficial risk profile; } \\
\text { Cluster 3, highest age }\end{array}$ & $\begin{array}{l}\text { Heterogeneous distribution of } \\
\text { clusters across countries }\end{array}$ & [39] \\
\hline $\begin{array}{l}\text { Electronic medical } \\
\text { records of a tertiary } \\
\text { diabetes centre, India } \\
(19,804 \text { people with T2D; } \\
\text { diabetes duration } \\
<5 \text { years })\end{array}$ & $\begin{array}{l}\text { Age at diagnosis, BMI, WC, } \mathrm{HbA}_{1 \mathrm{c}} \text {, } \\
\text { triacylglycerols, } \\
\text { HDL-cholesterol, C-peptide } \\
\text { (fasting and stimulated) }\end{array}$ & $\begin{array}{l}\text { Four clusters: Cluster 1, SIDD; } \\
\text { Cluster 2, IROD; Cluster 3, } \\
\text { CIRDD; Cluster 4, MARD }\end{array}$ & $\begin{array}{l}\text { SIDD and MARD similar to } \\
\text { diabetes subgroups in other } \\
\text { populations } \\
\text { IROD and CIRDD unique to Asian } \\
\text { Indian population } \\
\text { IROD showed highest BMI and } \\
\text { highest C-peptide levels } \\
\text { CIRRD showed lowest age of onset, } \\
\text { highest serum triacylglycerols, } \\
\text { highest risk for kidney disease }\end{array}$ & [40] \\
\hline $\begin{array}{l}\text { Retrospective } \\
\text { clinic-based study } \\
\text { sample, PR China } \\
\text { (5414 people with T2D; } \\
\text { mean diabetes duration } \\
8.6 \text { years) }\end{array}$ & $\begin{array}{l}\text { Age at diagnosis, BMI, } \mathrm{HbA}_{1 \mathrm{c}}, \\
\text { HOMA-2 estimates of beta cell } \\
\text { function and insulin resistance, } \\
\text { GADA; additional model with } \\
\text { triacylglycerols and uric acid }\end{array}$ & $\begin{array}{l}\text { Replication of SAID, SIRD and } \\
\text { MARD when using the original } \\
\text { six clustering variables } \\
\text { Replication of SAID, SIDD, SIRD, } \\
\text { MOD and MARD and } \\
\text { identification of novel subgroups } \\
\text { (UARD, IRD) when all clustering } \\
\text { variables were used }\end{array}$ & $\begin{array}{l}\text { Higher risk for retinopathy, } \\
\text { peripheral neuropathy, } \\
\text { hypertension and CKD for SIRD } \\
\text { (vs IRD) } \\
\text { Higher risk for retinopathy and } \\
\text { diabetic foot for SIDD (vs IRD) }\end{array}$ & {$[41]$} \\
\hline
\end{tabular}


Table 2 (continued)

\begin{tabular}{|c|c|c|c|c|}
\hline Cohort characteristic & Clustering variables & Subgroups & Specific findings & Ref. \\
\hline $\begin{array}{l}\text { Three global } \\
\text { cardiovascular } \\
\text { outcomes trials: } \\
\text { DEVOTE, LEADER, } \\
\text { SUSTAIN-6 } \\
\text { (20,274 people with T2D; } \\
\text { follow-up of } \\
\text { 2.0-3.8 years) }\end{array}$ & Age at diagnosis, $\mathrm{BMI}, \mathrm{HbA}_{1 \mathrm{c}}$ & $\begin{array}{l}\text { Identification of four subgroups: } \\
\text { clusters A-D }\end{array}$ & $\begin{array}{l}\text { Differences between clusters for } \\
\text { major adverse cardiovascular } \\
\text { events, cardiovascular death, } \\
\text { nephropathy and severe } \\
\text { hypoglycaemia when comparing } \\
\text { subgroups in at least one cohort }\end{array}$ & {$[42]$} \\
\hline
\end{tabular}

CIRDD, combined insulin-resistant and deficient diabetes; DCS, Diabetes Care System; DEVOTE, Trial Comparing Cardiovascular Safety of Insulin Degludec vs Insulin Glargine in Patients With Type 2 Diabetes at High Risk of Cardiovascular Events; EOD, early-onset diabetes; GADA, GAD antibodies; GoDARTS, Genetics of Diabetes Audit and Research; IRD, inheritance-related diabetes; IROD, insulin-resistant obese diabetes; LEADER, Liraglutide Effect and Action in Diabetes: Evaluation of Cardiovascular Outcome Results; MASALA, Mediators of Atherosclerosis in South Asians Living in America; MD, mild diabetes; MDH, mild diabetes with high cholesterol; MESA, Multi-Ethnic Study of Atherosclerosis; METS-IR, Metabolic score for insulin resistance; METS-VF, metabolic score for visceral fat; NHANES, National Health and Nutrition Examination Survey; OIRD, obese insulin-resistant diabetes; SUSTAIN-6, Trial to Evaluate Cardiovascular and Other Long-term Outcomes With Semaglutide in Subjects With Type 2 Diabetes; T2D, type 2 diabetes; UARD, uric acid-related diabetes; WC, waist circumference

effects on gene expression [48, 49]. (Epi)genetic variation and its impact on transcriptomes in immune cells will require more detailed analyses with respect to relevance in disease aetiology in the other subgroups.

Genetic predisposition There is evidence that the subgroups may differ in their associations with gene variants predisposing to diabetes. The HLA SNP rs 2854275 showed the same association with SAID as with type 1 diabetes in previous studies, but not with SIDD, pointing towards different aetiologies of insulin deficiency in the subgroups [6]. Both the TCF7L2 SNP rs7903146, which is known for its association with type 2 diabetes, and a genetic score for type 2 diabetes were associated with SIDD, MOD and MARD but not with SIRD [6]. A genetic risk score for insulin secretion was associated with MOD and MARD (and nominally with SIDD) but again not with SIRD [6]. This suggests a more pronounced role for genetic predisposition to SIDD, MOD and MARD and a stronger role for environmental determinants in SIRD. Of note, individuals with SIRD were more frequently carriers of the G allele of rs738409 in PNPLA3, the gene encoding patatin-like phospholipase domain-containing-3, which is characterised by its positive association with hepatic fat content [43] and may contribute to the relationship between SIRD and progression of NAFLD to fibrosis $[6,26,29]$. Thus, genetic analyses corroborate the difference between SAID and the other subgroups but suggest unique mechanisms that might distinguish SIRD from SIDD, MOD and MARD.

At present, the only study integrating genetic, metabolomic, lipidomic and proteomic data to compare diabetes subtypes was based on different clustering variables (age, BMI, $\mathrm{HbA}_{1 \mathrm{c}}$, HDL-cholesterol, and random or fasting Cpeptide). SIRD showed the most distinct molecular signature, mostly related to insulin resistance, lipids and inflammation [50].

\section{Subgroups of individuals with different risk of progression to type 2 diabetes and complications}

Trajectory analyses show that changes in metabolic and inflammation-related biomarkers start $>10$ years before the onset of type 2 diabetes [51-53]. Therefore, it is also of high clinical relevance to identify subgroups of individuals at different risk for diabetes and for complications, which may start even before the manifestation of diabetes. Latent-class trajectory analysis using OGTTs in people without diabetes revealed four subgroups that differed in anthropometric, metabolic and inflammation-related variables [24], but this study did not analyse diabetes-related complications.

A recent study in a cohort of individuals at elevated risk of type 2 diabetes explored the pathophysiological heterogeneity before clinical diabetes onset [23]. Participants from the Tübingen Family Study (TUEF) and Tübingen Lifestyle Intervention Program (TULIP) underwent clustering based on OGTT, MRI (body fat distribution, liver fat), serum lipids and a PRS for type 2 diabetes. This study found six subphenotypes differing in diabetes-related variables: 1 , low risk; 2 , very low risk; 3 , beta cell failure; 4 , low-risk obese; 5 , high-risk insulinresistant fatty liver; 6, high-risk visceral fat nephropathy [23]. Results were replicated in the Whitehall II cohort using a reduced set of clustering variables. Overall, clusters 3, 5 and 6 showed higher glucose levels at baseline but only clusters 3 and 5 had an increased incidence of type 2 diabetes. Clusters 3, 5 and 6 featured the highest CKD risk and higher intima-media thickness, and clusters 5 and 6 had the highest all-cause mortality. Data from Whitehall II indicated that individuals from the lowrisk clusters 1, 2 and 4 transitioned to MOD and MARD with diabetes onset, whereas individuals from the high-risk cluster 6 transitioned to SIRD [23]. Thus, clustering approaches can also identify subphenotypes with respect to glycaemic, renal, 
cardiovascular and all-cause mortality risk, corresponding to previous findings for overt diabetes $[6,26]$.

\section{Translation into clinical practice: therapeutic implications}

RCTs are required to evaluate the clinical relevance of reclassification efforts. Until data from subgroup-specific RCTs are available, it is only possible to investigate in cohort studies [6, 29] or intervention trials, such as A Diabetes Outcome Progressive Trial (ADOPT) [28], whether individuals allocated to subgroups differ in their treatment at study baseline or their treatment responses, respectively (Table 3). Importantly, the high frequency of individuals without initial glucose-lowering treatment, the low frequency of insulin use and the shortest time to reach the $\mathrm{HbA}_{1 \mathrm{c}}$ target were similar for SIRD, MOD and MARD and correspond to their less pronounced insulin deficiency compared with SAID and SIDD (Table 3). Glycaemic deterioration may thus suggest a milder progression of disease for SIRD, MOD and MARD. However, the higher risk for several complications in SIRD clearly indicates the need for treatment intensification addressing CKD, CVD and NAFLD (e.g. by sodiumglucose cotransporter 2 inhibitors [SGLT2is] and glucagon-like peptide-1 receptor agonists [GLP-1RAs]), as well as targeting insulin resistance (e.g. by future insulin sensitisers) (Fig. 1). Given the proinflammatory profile and the high risk of complications in SIRD, novel therapies targeting inflammatory pathways, as developed for people at high cardiovascular risk [54, 55], could also be considered in the future. Initially, lifestyle modification and metformin are sufficient for treating MOD and MARD. Nevertheless, MOD may specifically benefit from weight loss intervention by hypo-energetic diets and drugs, whereas MARD may be better treated by nutrition avoiding further ageing-related sarcopenia (Fig. 1).

Currently, it is not clear whether our knowledge on mechanisms (and adverse effects) of these drugs will translate into subgroup-specific treatment benefits [56]. However, the large number of ongoing RCTs using novel therapeutic agents targeting insulin secretion, insulin resistance, liver metabolism and other mechanisms that differ between the subgroups holds promise for precision healthcare [57].

So far, only the Look AHEAD (Action for Health in Diabetes) study analysed the differential response to lifestyle intervention [37]. Individuals with type 2 diabetes were allocated to four subgroups, which are not directly comparable with the previously described subgroups $[6,26]$ due to differences in clustering variables. Randomisation to intensive lifestyle intervention was associated with increased cardiovascular risk in the subgroup characterised by the poorest glucose control and most frequent

Table 3 Novel diabetes subgroups: glucose-lowering therapy in cohort studies and response to therapy in ADOPT

\begin{tabular}{|c|c|c|c|}
\hline $\begin{array}{l}\text { Diabetes } \\
\text { subgroup }\end{array}$ & Therapy in cohort studies & Response to therapy in ADOPT & Comment \\
\hline SAID & $\begin{array}{l}\text { Most frequent use of insulin and lowest use of } \\
\text { metformin at baseline }[6,29] \\
\text { Shortest time to sustained insulin use [6] }\end{array}$ & $\begin{array}{l}\text { Not analysed in the context of novel diabetes } \\
\text { subgroups }\end{array}$ & $\begin{array}{l}\text { Findings are in line with the established } \\
\text { treatment for type } 1 \text { diabetes and } \\
\text { LADA }\end{array}$ \\
\hline SIDD & $\begin{array}{l}\text { Most frequent use of metformin at baseline } \\
{[8,29]} \\
\text { Frequent use of insulin at baseline and short time } \\
\text { to sustained insulin use, although less } \\
\text { pronounced than for SAID [6] } \\
\text { Shortest time to treatment with oral medication } \\
\text { other than metformin and longest time to reach } \\
\mathrm{HbA}_{1 \mathrm{c}} \text { treatment goal [6] }\end{array}$ & $\begin{array}{l}\text { Initial treatment response best with } \\
\text { sulfonylureas but highest } \mathrm{HbA}_{1 \mathrm{c}} \text { increase } \\
\text { thereafter with sulfonylureas }\end{array}$ & $\begin{array}{l}\text { Data are in line with the low beta cell } \\
\text { reserves in this subgroup }\end{array}$ \\
\hline SIRD & $\begin{array}{l}\text { Most frequently treated with metformin or } \\
\text { without glucose-lowering therapy [6] } \\
\text { Evidence for higher insulin use later after } \\
\text { diabetes diagnosis [29] }\end{array}$ & $\mathrm{HbA}_{1 \mathrm{c}}$ benefit with thiazolidinedione therapy & $\begin{array}{l}\text { Findings are plausible given the } \\
\text { pronounced insulin resistance and high } \\
\text { prevalence of NAFLD in SIRD }\end{array}$ \\
\hline MOD & $\begin{array}{l}\text { Most frequently treated with metformin or } \\
\text { without glucose-lowering therapy [6] } \\
\text { Lowest baseline use of insulin [29] }\end{array}$ & $\begin{array}{l}\text { Initial treatment response best with } \\
\text { sulfonylureas but highest } \mathrm{HbA}_{1 \mathrm{c}} \text { increase } \\
\text { thereafter with sulfonylureas }\end{array}$ & $\begin{array}{l}\text { Data indicate a mild form and mild } \\
\text { progression of diabetes }\end{array}$ \\
\hline MARD & $\begin{array}{l}\text { Most frequently treated with metformin or } \\
\text { without glucose-lowering therapy [6] } \\
\text { Low cumulative incidence of treatment with oral } \\
\text { medication other than metformin or of } \\
\text { sustained insulin use [6] }\end{array}$ & $\begin{array}{l}\mathrm{HbA}_{1 \mathrm{c}} \text { benefit with sulfonylurea therapy, } \\
\text { limited to about } 2 \text { years, vs metformin and } \\
\text { thiazolidinedione treatment }\end{array}$ & $\begin{array}{l}\text { Data indicate a mild form and mild } \\
\text { progression of diabetes }\end{array}$ \\
\hline
\end{tabular}

Data for response to therapy in ADOPT are from a secondary analysis of the trial [28], which randomised newly diagnosed, drug-naive individuals with type 2 diabetes to metformin, sulfonylurea (glibenclamide) or thiazolidinedione (rosiglitazone) monotherapy

LADA, latent autoimmune diabetes of adults 


\section{Gaps in the current knowledge, open questions and future research directions}

- The proposed novel diabetes subgroups [6] are partly based on fasting C-peptide, which is not always available, so the selection of clustering variables should be optimised to ensure simple and reproducible clinical measures

- The original cluster algorithm assessed autoimmunity only by measuring GADA [6]; adding other isletdirected antibodies will expand the subgroup with autoimmune diabetes [26]

- Some people with diabetes migrate between diabetes subgroups over time [26, 38]. More studies investigating this phenomenon and linking it to disease progression are warranted to assess the stability of subgroup allocation and its impact on the utility of this concept

- Different strategies have been proposed to reclassify diabetes [58,59]. Future studies should compare the clinical utility of distinct diabetes subgroups and probabilistic models using continuous risk factors for the prediction of complications and treatment response. Irrespective of the underlying statistical method, the practicability in clinical care of different treatment decisions depending on reclassification needs to be proven

- Both phenotypic and genotypic data could be used to reclassify diabetes [6, 22]. Given the wide age range of diabetes onset across the lifespan both approaches may be complementary but with different relative contributions to risk prediction depending on age

- Biomarker studies (e.g. on biomarkers of inflammation) point towards pathomechanisms that differ between diabetes subgroups [43, 46, 47]. An extension of phenotyping including not only multiple omics data (e.g. genomics, metabolomics, proteomics, transcriptomics) but also deep molecular and physiological phenotyping using wearable devices may help to provide further insight and to refine the subtyping of diabetes [10, 60-62]

- Individual responses to diet and exercise vary between individuals [63,64]. It is not known to what extent this individuality is also related to different pathomechanisms that characterise the novel diabetes subgroups

- The five diabetes subgroups were developed using data from European cohorts [6] but diabetes phenotypes and drug responses can differ between ethnic groups [59,65,66]. Replication studies in nonWhite people with diabetes identified additional subgroups but were often based on different sets of clustering variables and/or diabetes durations [27, 29, 30, 36, 38-41]. Overall, the applicability of the subgroup concept in the general population and in different ethnic groups requires further study

- Studies have focused so far on associations between diabetes subgroups and objective clinical measures but also need to take into account patient-centred mental health and quality-of-life outcomes [13]

- Given the novel findings on subgroups with different risk trajectories among people with and without diabetes [6,23], future investigations should assess whether individuals in these subgroups require not only different intensities in drug treatment or lifestyle intervention programmes but also different intervals in screening and monitoring for complications

- If it becomes a requirement for the approval of new drugs to demonstrate whether they are equally effective in different subgroups or just recommended for specific subgroups, smaller market shares for precision medicines may entail challenges for future drug development [67]

use of insulin [37]. Thus, subgroups may differ in their response to non-pharmacological treatment, emphasising the differential need for pharmacological treatment intensification to prevent diabetes-related complications.

\section{Methodological aspects and open questions}

The text box above gives an overview of key gaps in our current knowledge, resulting open questions, and future 


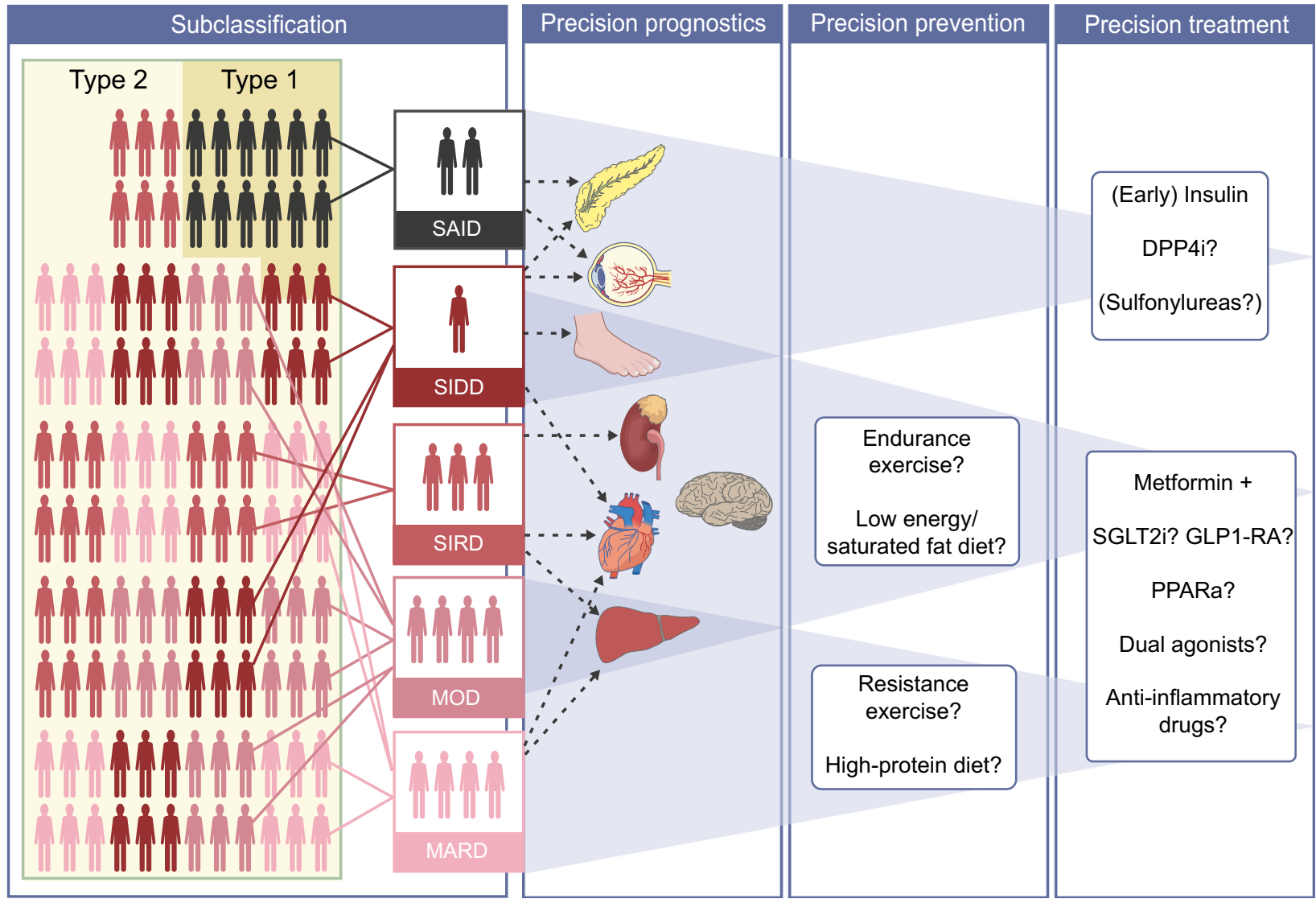

Fig. 1 Possible future implications of precision diabetology based on the novel diabetes subgroups. Although the utility of the concept needs to be evaluated in RCTs, one may speculate on the potential implications of a new (sub)classification of diabetes for tailored diagnosis, prevention and treatment. Individuals in the different diabetes subgroups differ in their susceptibility to developing specific complications. The different (pathophysiological) phenotypes may also differ in their response to lifestylerelated and pharmacological strategies. SAID requires early introduction of insulin supplementation, whereas SIDD may also benefit from a dipeptidyl peptidase 4 inhibitor (DPP4i) or, when cost is a major issue, a sulfonylurea. SIRD and MOD would benefit from medication that induces weight loss (SGLT2i, GLP-1RA, dual agonist) or also addresses risk of CVD or nephropathy (SGLT2i, GLP-1RA). Providing that safety and efficacy have been established, new insulin sensitisers (e.g. peroxisome proliferator activator receptor agonists) or anti-inflammatory drugs could also improve targeted treatment of SIRD. On the other hand, individuals with MARD should receive treatments avoiding weight loss and sarcopenia (e.g. protein-balanced diets and moderate resistance training). PPARa, peroxisome proliferator activator receptor agonist. This figure is available as a downloadable slide directions in this field; some of the methodological aspects are also briefly discussed here. Any effort made concerning reclassification into subgroups has a strong conceptual appeal because it is easy to communicate and implement once RCTs have shown subgroup-specific differences to non-pharmacological and pharmacological interventions. However, this approach assumes a certain degree of homogeneity within, and clear differences between, subgroups, whereas in reality the characteristics of individuals from different clusters partially overlap [3]. The subgroup approach is also limited by the fact that subgroup assignment requires the availability of all clustering variables. Finally, the utility of subgroups depends on their stability. An analysis in the GDS demonstrated that $23 \%$ of the study participants migrated into a different subgroup within the first 5 years after the diagnosis of diabetes [26].
An alternative strategy in precision diabetology may be based on statistical models using continuous risk factors [28, $58,68]$. In a secondary analysis of RCTs [28], age at diabetes diagnosis and renal function at baseline were better predictors of disease progression than the subgroup assignment according to Ahlqvist et al [6]. Thus, specific phenotypic measures to predict glycaemic progression, onset of complications and treatment response could be used to optimise diabetes care in an individualised approach. The risk assessment could be updated regularly to take into account disease progression, with corresponding treatment changes. However, these models would only be useful for optimising one specific outcome such as glycaemic progression or the development of a predefined complication unless they were a priori designed to predict a composite endpoint comprising different outcomes based on the patients' preferences. Currently, such an approach remains 
challenging because it requires a huge amount of individualparticipant data to develop the underlying models.

One general criticism of the aforementioned reclassification strategies refers to their use of phenotypic data that depend on disease progression, lifestyle and medication and therefore necessitate regular adaptation. In contrast, genotypic data are stable over time and are more likely to be related to causal mechanisms [22]. However, the proportion of diabetes risk that can be explained by environmental risk factors is still greater than the proportion that can be attributed to known genetic risk variants. This means that people with large differences in genetic risk scores show minor phenotypic differences that can be overcome by modifying exogenous risk factors [69, 70]. Currently, it is unknown which of the two approaches or alternatively a combination of both phenotypic and genotypic reclassification would provide the best benefit.

Irrespective of all methodological and practical issues, it is important to emphasise the following points: (1) clinical decision making is always binary at the end (i.e. resulting in the decision to treat or not to treat and in the selection of certain nonpharmacological or pharmacological interventions) and (2) any approach to reclassify diabetes must result in diabetes prevention and care superior to that received under the established classification. The ongoing initiative of the ADA and the EASD on precision medicine in diabetes will provide a detailed roadmap for future studies and application of tailored diagnostics, prevention and treatment on the road to precision diabetology [13].

\section{Conclusions}

The heterogeneity of diabetes, particularly type 2 diabetes, is evident from differences in multiple pathophysiological and clinical features. Recent studies provided novel insights into interindividual differences by clustering people with diabetes into five subgroups, which are reproducible and associated with different trajectories in disease progression and onset of diabetes-related complications including $\mathrm{CKD}$, retinopathy, CVD, NAFLD and neuropathies. Based on the current evidence, it is possible to propose innovative stratified prevention and treatment approaches at least for some of these subgroups (Fig. 1). However, the ultimate test of the utility of precision diabetology will require RCTs to demonstrate whether the probability-based assignment to subgroups and subsequent subgroup-specific prevention or treatment is indeed superior to that proposed by the current guidelines. Furthermore, future studies should address methodological issues, in particular on the best precision diabetology approaches, and also uncertainties regarding the transethnic generalisability of the current findings.

Electronic supplementary material The online version of this article (https://doi.org/10.1007/s00125-021-05625-x) contains peer-reviewed but unedited supplementary material including a slide of the figure for download, which is available to authorised users.

Funding Open Access funding enabled and organized by Projekt DEAL. The German Diabetes Center (DDZ) is supported by the Ministry of Culture and Science of the State of North Rhine-Westphalia and the German Federal Ministry of Health. This work was supported in part by a grant from the German Federal Ministry of Education and Research to the German Center for Diabetes Research (DZD).

Authors' relationships and activities $\mathrm{CH}$ received a research grant from Sanofi-Aventis outside the submitted work. $\mathrm{CH}$ is a member of the editorial board of Diabetologia. MR received fees as a member of advisory boards or as a speaker from Allergan, Boehringer Ingelheim Pharma, Bristol-Myers Squibb, Eli Lilly, Fishawack Group, Gilead Sciences, Novartis Pharma, Intercept Pharma, Inventiva, Novo Nordisk, Target NASH and Terra Firma, and has been involved with clinical trial research for Boehringer Ingelheim, Danone Nutricia Research and Sanofi-Aventis, all outside the submitted work.

Contribution statement Both authors were responsible for drafting the article and revising it critically for important intellectual content. Both authors approved the version to be published.

Open Access This article is licensed under a Creative Commons Attribution 4.0 International License, which permits use, sharing, adaptation, distribution and reproduction in any medium or format, as long as you give appropriate credit to the original author(s) and the source, provide a link to the Creative Commons licence, and indicate if changes were made. The images or other third party material in this article are included in the article's Creative Commons licence, unless indicated otherwise in a credit line to the material. If material is not included in the article's Creative Commons licence and your intended use is not permitted by statutory regulation or exceeds the permitted use, you will need to obtain permission directly from the copyright holder. To view a copy of this licence, visit http://creativecommons.org/licenses/by/4.0/.

\section{References}

1. Gale EA (2001) The discovery of type 1 diabetes. Diabetes 50(2): 217-226. https://doi.org/10.2337/diabetes.50.2.217

2. Gale EA (2013) Is type 2 diabetes a category error? Lancet 381(9881): 1956-1957. https://doi.org/10.1016/S0140-6736(12)62207-7

3. McCarthy MI (2017) Painting a new picture of personalised medicine for diabetes. Diabetologia 60(5):793-799. https://doi.org/10. 1007/s00125-017-4210-x

4. Pearson ER (2019) Type 2 diabetes: a multifaceted disease. Diabetologia 62(7):1107-1112. https://doi.org/10.1007/s00125019-4909-y

5. Szendroedi J, Saxena A, Weber KS et al (2016) Cohort profile: the German diabetes study (GDS). Cardiovasc Diabetol 15:59. https:// doi.org/10.1186/s12933-016-0374-9

6. Ahlqvist E, Storm P, Käräjämäki A et al (2018) Novel subgroups of adult-onset diabetes and their association with outcomes: a datadriven cluster analysis of six variables. Lancet Diabetes Endocrinol 6(5):361-369. https://doi.org/10.1016/S2213-8587(18)30051-2

7. Davies MJ, D'Alessio DA, Fradkin J et al (2018) Management of hyperglycaemia in type 2 diabetes, 2018. A consensus report by the American Diabetes Association (ADA) and the European Association for the Study of diabetes (EASD). Diabetologia 61(12):2461-2498. https://doi.org/10.1007/s00125-018-4729-5 Erratum in: Diabetologia 2019;62(5):873 
8. Redondo MJ, Hagopian WA, Oram R et al (2020) The clinical consequences of heterogeneity within and between different diabetes types. Diabetologia 63(10):2040-2048. https://doi.org/10.1007/ s00125-020-05211-7

9. Bonora E, Trombetta M, Dauriz M et al (2020) Chronic complications in patients with newly diagnosed type 2 diabetes: prevalence and related metabolic and clinical features: the Verona newly diagnosed type 2 diabetes study (VNDS) 9. BMJ Open Diabetes Res Care 8(1):e001549. https://doi.org/10.1136/bmjdrc-2020-001549

10. Prasad RB, Groop L (2019) Precision medicine in type 2 diabetes. J Intern Med 285(1):40-48. https://doi.org/10.1111/joim.12859

11. Gloyn AL, Drucker DJ (2018) Precision medicine in the management of type 2 diabetes. Lancet Diabetes Endocrinol 6(11):891900. https://doi.org/10.1016/S2213-8587(18)30052-4

12. Barroso I, McCarthy MI (2019) The genetic basis of metabolic disease. Cell 177(1):146-161. https://doi.org/10.1016/j.cell.2019.02.024

13. Chung WK, Erion K, Florez JC et al (2020) Precision medicine in diabetes: a consensus report from the American Diabetes Association (ADA) and the European Association for the Study of diabetes (EASD). Diabetologia 63(9):1671-1693. https://doi. org/10.1007/s00125-020-05181-w

14. Battaglia M, Ahmed S, Anderson MS et al (2020) Introducing the Endotype concept to address the challenge of disease heterogeneity in type 1 diabetes. Diabetes Care 43(1):5-12. https://doi.org/10. 2337/dc19-0880

15. Zoppini G, Cacciatori V, Raimondo D et al (2015) Prevalence of cardiovascular autonomic neuropathy in a cohort of patients with newly diagnosed type 2 diabetes: the Verona newly diagnosed type 2 diabetes study (VNDS). Diabetes Care 38(8):1487-1493. https:// doi.org/10.2337/dc15-0081

16. Zaharia OP, Bobrov P, Strassburger K et al (2018) Metabolic characteristics of recently diagnosed adult-onset autoimmune diabetes mellitus. J Clin Endocrinol Metab 103(2):429-437. https://doi.org/ 10.1210/jc.2017-01706

17. Maalmi H, Herder C, Strassburger K et al (2020) Biomarkers of inflammation and glomerular filtration rate in individuals with recent-onset type 1 and type 2 diabetes. J Clin Endocrinol Metab 105(12):e4370-e4381. https://doi.org/10.1210/clinem/dgaa622

18. Zoppini G, Trombetta M, Pastore I et al (2021) Glomerular filtration rate decline in T2DM following diagnosis. The Verona newly diagnosed diabetes Study-12. Diabetes Res Clin Pract 22:108778. https://doi.org/10.1016/j.diabres.2021.108778

19. Mahajan A, Taliun D, Thurner M et al (2018) Fine-mapping type 2 diabetes loci to single-variant resolution using high-density imputation and islet-specific epigenome maps. Nat Genet 50(11):15051513. https://doi.org/10.1038/s41588-018-0241-6

20. Sarría-Santamera A, Orazumbekova B, Maulenkul T, Gaipov A, Atageldiyeva K (2020) The identification of diabetes mellitus subtypes applying cluster analysis techniques: a systematic review. Int J Environ Res Public Health 17(24):9523. https://doi.org/10. 3390/ijerph17249523

21. Li L, Cheng WY, Glicksberg BS et al (2015) Identification of type 2 diabetes subgroups through topological analysis of patient similarity. Sci Transl Med 7(311):311ra174. https://doi.org/10.1126/ scitranslmed.aaa9364

22. Udler MS, Kim J, von Grotthuss M et al (2018) Type 2 diabetes genetic loci informed by multi-trait associations point to disease mechanisms and subtypes: a soft clustering analysis. PLoS Med 15(9):e1002654. https://doi.org/10.1371/journal.pmed.1002654

23. Wagner R, Heni M, Tabák AG et al (2021) Pathophysiology-based subphenotyping of individuals at elevated risk for type 2 diabetes. Nat Med 27(1):49-57. https://doi.org/10.1038/s41591-020-1116-9

24. Hulman A, Witte DR, Vistisen D et al (2018) Pathophysiological characteristics underlying different glucose response curves: a latent class trajectory analysis from the prospective EGIR-RISC study. Diabetes Care 41(8):1740-1748. https://doi.org/10.2337/ dc18-0279

25. Obura M, Beulens JWJ, Slieker R et al (2020) Post-load glucose subgroups and associated metabolic traits in individuals with type 2 diabetes: an IMI-DIRECT study. PLoS One 15(11):e0242360. https://doi.org/10.1371/journal.pone.0242360

26. Zaharia OP, Strassburger K, Strom A et al (2019) Risk of diabetesassociated diseases in subgroups of patients with recent-onset diabetes: a 5-year follow-up study. Lancet Diabetes Endocrinol 7(9):684-694. https://doi.org/10.1016/S2213-8587(19)30187-1

27. Zou X, Zhou X, Zhu Z, Ji L (2019) Novel subgroups of patients with adult-onset diabetes in Chinese and US populations. Lancet Diabetes Endocrinol 7(1):9-11. https://doi.org/10.1016/S22138587(18)30316-4

28. Dennis JM, Shields BM, Henley WE, Jones AG, Hattersley AT (2019) Disease progression and treatment response in data-driven subgroups of type 2 diabetes compared with models based on simple clinical features: an analysis using clinical trial data. Lancet Diabetes Endocrinol 7(6):442-451. https://doi.org/10. 1016/S2213-8587(19)30087-7

29. Tanabe H, Saito H, Kudo A et al (2020) Factors associated with risk of diabetic complications in novel cluster-based diabetes subgroups: a Japanese retrospective cohort study. J Clin Med 9(7):2083. https://doi.org/10.3390/jcm9072083

30. Bennet L, Nilsson C, Mansour-Aly D, Christensson A, Groop L (2020) Ahlqvist E (2020) adult-onset diabetes in middle eastern immigrants to Sweden: novel subgroups and diabetic complications-the all new diabetes in Scania cohort diabetic complications and ethnicity. Diabetes Metab Res Rev 29:e3419. https://doi.org/10.1002/dmrr.3419

31. Fedotkina O, Sulaieva O, Ozgumus T et al (2021) Novel reclassification of adult diabetes is useful to distinguish stages of $\beta$-cell function linked to the risk of vascular complications: the DOLCE study from northern Ukraine. Front Genet 12:637945. https://doi. org/10.3389/fgene.2021.637945

32. Xing L, Peng F, Liang Q et al (2021) Clinical characteristics and risk of diabetic complications in data-driven clusters among type 2 diabetes. Front Endocrinol (Lausanne) 12:617628. https://doi.org/ 10.3389 /fendo.2021.617628

33. Maalmi H, Herder C, Bönhof GJ et al (2021) Differences in the prevalence of erectile dysfunction between novel subgroups of recent-onset diabetes. Diabetologia. https://doi.org/10.1007/ s00125-21-05607-z (in press)

34. Bonadonna RC, Trombetta M, Zusi C, Dauriz M, Boselli ML, Bonora E (2019) Novel subgroups of type 2 diabetes at diagnosis in a southern European cohort. Diabetes 68(Supplement 1):1502-P (abstract). https://doi.org/10.2337/db19-1502-P

35. Slieker RC, Donnelly LA, Fitipaldi $\mathrm{H}$ et al (2021) Replication and cross-validation of type 2 diabetes subtypes based on clinical variables: an IMI-RHAPSODY study. Diabetologia 64(9):1982-1989. https://doi.org/10.1007/s00125-021-05490-8

36. Bancks MP, Bertoni AG, Carnethon M et al (2021) Association of Diabetes Subgroups with Race/ethnicity, risk factor burden and complications: the MASALA and MESA studies. J Clin Endocrinol Metab 106(5):e2106-e2115. https://doi.org/10.1210/clinem/dgaa962

37. Bancks MP, Chen H, Balasubramanyam A et al (2021) Type 2 diabetes subgroups, risk for complications, and differential effects due to an intensive lifestyle intervention. Diabetes Care 44(5): 1203-1210. https://doi.org/10.2337/dc20-2372

38. Bello-Chavolla OY, Bahena-López JP, Vargas-Vázquez A et al (2020) Clinical characterization of data-driven diabetes subgroups in Mexicans using a reproducible machine learning approach. BMJ Open Diabetes Res Care 8(1):e001550. https://doi.org/10.1136/ bmjdrc-2020-001550

39. Carrillo-Larco RM, Castillo-Cara M, Anza-Ramirez C, Bernabé-Ortiz A (2021) Clusters of people with type 2 diabetes in the general 
population: unsupervised machine learning approach using national surveys in Latin America and the Caribbean. BMJ Open Diabetes Res Care 9(1):e001889. https://doi.org/10.1136/bmjdrc-2020-001889

40. Anjana RM, Baskar V, Nair ATN et al (2020) Novel subgroups of type 2 diabetes and their association with microvascular outcomes in an Asian Indian population: a data-driven cluster analysis: the INSPIRED study. BMJ Open Diabetes Res Care 8(1):e001506. https://doi.org/10.1136/bmjdrc-2020-001506

41. Xiong XF, Yang Y, Wei L, Xiao Y, Li L, Sun L (2021) Identification of two novel subgroups in patients with diabetes mellitus and their association with clinical outcomes: a two-step cluster analysis. J Diabetes Investig 12(8):1346-1358. https://doi.org/10.1111/jdi.13494

42. Kahkoska AR, Geybels MS, Klein KR et al (2020) Validation of distinct type 2 diabetes clusters and their association with diabetes complications in the DEVOTE, LEADER and SUSTAIN-6 cardiovascular outcomes trials. Diabetes Obes Metab 22(9):1537-1547. https://doi.org/10.1111/dom.14063

43. Zaharia OP, Strassburger K, Knebel B et al (2020) Role of Patatinlike phospholipase domain-containing 3 gene for hepatic lipid content and insulin resistance in diabetes. Diabetes Care 43(9): 2161-2168. https://doi.org/10.2337/dc20-0329

44. Zou H, Duan W, Zhang Z, Chen X, Lu P, Yu X (2020) The circulating ANGPTL8 levels show differences among novel subgroups of adult patients with diabetes and are associated with mortality in the subsequent 5 years. Sci Rep 10(1):12859. https://doi.org/10. 1038/s41598-020-69091-y

45. Roden M, Shulman GI (2019) The integrative biology of type 2 diabetes. Nature 576(7785):51-60. https://doi.org/10.1038/s41586019-1797-8

46. Herder C, Maalmi H, Strassburger K et al (2021) Differences in biomarkers of inflammation between novel subgroups of recentonset diabetes. Diabetes 70(5):1198-1208. https://doi.org/10. 2337/db20-1054

47. Ratter-Rieck JM, Maalmi H, Trenkamp S et al (2021) Leukocyte counts and $\mathrm{T}$ cell frequencies differ between novel subgroups of diabetes and associate with metabolic parameters and biomarkers of inflammation. Diabetes 30:db210364. https://doi.org/10.2337/ $\mathrm{db} 21-0364$

48. Fasolino M, Goldman N, Wang W et al (2020) Genetic variation in type 1 diabetes reconfigures the 3D chromatin Organization of $\mathrm{T}$ Cells and Alters Gene Expression. Immunity 52(2):257-274.e11. https://doi.org/10.1016/j.immuni.2020.01.003

49. Gao P, Uzun Y, He B et al (2019) Risk variants disrupting enhancers of $\mathrm{T}_{\mathrm{H}} 1$ and $\mathrm{T}_{\mathrm{REG}}$ cells in type 1 diabetes. Proc Natl Acad Sci U S A 116(15):7581-7590. https://doi.org/10.1073/ pnas. 1815336116

50. Slieker RC, Donnelly LA, Fitipaldi H et al (2021) Distinct molecular signatures of clinical clusters in people with type 2 diabetes: an IMIRHAPSODY study. Diabetes 10:db201281. https://doi.org/10. 2337/db20-1281

51. Tabák AG, Jokela M, Akbaraly TN, Brunner EJ, Kivimäki M, Witte DR (2009) Trajectories of glycaemia, insulin sensitivity, and insulin secretion before diagnosis of type 2 diabetes: an analysis from the Whitehall II study. Lancet 373(9682):2215-2221. https://doi.org/10.1016/S0140-6736(09)60619-X

52. Carstensen M, Herder C, Kivimäki M et al (2010) Accelerated increase in serum interleukin-1 receptor antagonist starts 6 years before diagnosis of type 2 diabetes: Whitehall II prospective cohort study. Diabetes 59(5):1222-1227. https://doi.org/10.2337/db09-1199

53. Tabák AG, Carstensen M, Witte DR et al (2012) Adiponectin trajectories before type 2 diabetes diagnosis: Whitehall II study. Diabetes Care 35(12):2540-2547. https://doi.org/10.2337/dc11-2263

54. Donath MY, Dinarello CA, Mandrup-Poulsen T (2019) Targeting innate immune mediators in type 1 and type 2 diabetes. Nat Rev Immunol 19(12):734-746. https://doi.org/10.1038/s41577-019-0213-9
55. Lawler PR, Bhatt DL, Godoy LC et al (2021) Targeting cardiovascular inflammation: next steps in clinical translation. Eur Heart J 42(1):113-131. https://doi.org/10.1093/eurheartj/ehaa099

56. Veelen A, Erazo-Tapia E, Oscarsson J, Schrauwen P (2021) Type 2 diabetes subgroups and potential medication strategies in relation to effects on insulin resistance and beta-cell function: a step toward personalised diabetes treatment? Mol Metab 46:101158. https://doi. org/10.1016/j.molmet.2020.101158

57. Perreault L, Skyler JS, Rosenstock J (2021) Novel therapies with precision mechanisms for type 2 diabetes mellitus. Nat Rev Endocrinol 17(6):364-377. https://doi.org/10.1038/s41574-021-00489-y

58. Dennis JM (2020) Precision medicine in type 2 diabetes: using individualized prediction models to optimize selection of treatment. Diabetes 69(10):2075-2085. https://doi.org/10.2337/dbi20-0002

59. Ahlqvist E, Prasad RB, Groop L (2020) Subtypes of type 2 diabetes determined from clinical parameters. Diabetes 69(10):2086-2093. https://doi.org/10.2337/dbi20-0001

60. Del Prato S (2019) Heterogeneity of diabetes: heralding the era of precision medicine. Lancet Diabetes Endocrinol 7(9):659-661. https://doi.org/10.1016/S2213-8587(19)30218-9

61. Schüssler-Fiorenza Rose SM, Contrepois K, Moneghetti KJ et al (2019) A longitudinal big data approach for precision health. Nat Med 25(5):792-804. https://doi.org/10.1038/s41591-019-0414-6

62. Khoshnejat M, Kavousi K, Banaei-Moghaddam AM, MoosaviMovahedi AA (2020) Unraveling the molecular heterogeneity in type 2 diabetes: a potential subtype discovery followed by metabolic modeling. BMC Med Genet 13(1):119. https://doi.org/10.1186/ s12920-020-00767-0

63. Berry SE, Valdes AM, Drew DA et al (2020) Human postprandial responses to food and potential for precision nutrition. Nat Med 26(6):964-973. https://doi.org/10.1038/s41591-020-0934-0

64. Contrepois K, Wu S, Moneghetti KJ et al (2020) Molecular choreography of acute exercise. Cell 181(5):1112-1130.e16. https://doi. org/10.1016/j.cell.2020.04.043

65. Lee MMY, Ghouri N, McGuire DK, Rutter MK, Sattar N (2021) Meta-analyses of results from randomized outcome trials comparing cardiovascular effects of SGLT2is and GLP-1RAs in Asian versus white patients with and without type 2 diabetes. Diabetes Care 44(5):1236-1241. https://doi.org/10.2337/dc20-3007

66. Redondo MJ, Balasubramanyam A (2021) Towards an improved classification of type 2 diabetes: lessons from research into the heterogeneity of a complex disease. J Clin Endocrinol Metab 22: dgab545. https://doi.org/10.1210/clinem/dgab545

67. Fitipaldi H, McCarthy MI, Florez JC, Franks PW (2018) A global overview of precision medicine in type 2 diabetes. Diabetes 67(10): 1911-1922. https://doi.org/10.2337/dbi17-0045

68. Lugner M, Gudbjörnsdottir S, Sattar N et al (2021) Comparison between data-driven clusters and models based on clinical features to predict outcomes in type 2 diabetes: nationwide observational study. Diabetologia 64(9):1973-1981. https://doi.org/10.1007/ s00125-021-05485-5

69. Langenberg C, Sharp SJ, Franks PW et al (2014) Gene-lifestyle interaction and type 2 diabetes: the EPIC interact case-cohort study. PLoS Med 11(5):e1001647. https://doi.org/10.1371/journal.pmed.1001647

70. Mahajan A, Taliun D, Thurner $\mathrm{M}$ et al (2018) Fine-mapping type 2 diabetes loci to single-variant resolution using high-density imputation and islet-specific epigenome maps. Nat Genet 50(11):15051513. https://doi.org/10.1038/s41588-018-0241-6

Publisher's note Springer Nature remains neutral with regard to jurisdictional claims in published maps and institutional affiliations. 